\title{
Views and Examples on Hyper-Connectivity
}

\author{
Jean-Gabriel Ganascia
}

\section{Preliminary}

There can be no doubt that the information and communication technologies (ICT) deeply impact the human society. The difficulty in appraising their effect and anticipating the concomitant changes lies in the depth of that impact. In an attempt to understand the present evolutions, we propose to uncover the underlying structure of this new world by revisiting its dependencies on the hyper-connectivity on which it is grounded, and the consequences of this hyper-connectivity, in modifying profoundly the network of inter-individual relations. Where we used to have ten to fifty close friends living near us, with whom we shared convivial relations, we may now have hundreds of acquaintances living on other continents, with whom we currently exchange specialized information about our main fields of interest that can be professional, artistic or related to any kind of hobby. It naturally follows from these major changes in the scale and nature of individual relationships, that the social fabric is dramatically evolving. Therefore, to quote Aristotle, since "man is by nature a social animal," humanity is changing because society is changing. But, how are humans and society changing? And, what does it mean to be human, in this new society? These are the questions we would like to address.

Besides, the hyper-connected world is also a world of hyper-memorisability, where all the information is stored in huge databases and accessible anytime from anywhere, without any oblivion. And, it is a world of hyper-reproducibility and hyper-diffusibility, where all the knowledge, and more generally, all the works of the mind, i.e. all the music, all the paintings, all the movies, etc. can be freely and massively reproduced and diffused. So, both the way in which individuals access knowledge and their internal memories are deeply modified, which transforms human cognitive abilities.

\section{J.-G. Ganascia $(\bowtie)$}

LIP6, University Pierre and Marie Curie,

Sorbonne Universités, Paris, France

e-mail: jean-gabriel.ganascia@lip6.fr 
However, we think that hyper-connectivity is the main factor of change, which means that, even if we face huge individual cognitive transformations, this will have far less influence on society than network connectivity. Our chapter investigates this point by referring to some concrete examples. More precisely, it first shows that the analysis of social networks cannot be reduced to a study of the topology of connections, but has to take into account the processes and their reciprocal dependences, e.g. their synchronicity or precedence relations. Then, it analyses the nature of present transformations on three examples that refer respectively to the change in our access to knowledge, to the change in the solidarity and assistance between people and, thirdly, to the status and nature of artistic work. In each case, the network influences power relationships. Old well-established authorities are questioned while new forms of domination emerge.

In other words, next to the three traditional Kantian questions, "What can I know?", "What ought I to do?" and "What may I hope?", we would like to answer three current questions, "How can I know now?", "How ought I to do, now?" and "How may I hope, now?", where "how" refers ways in which things are done and, more precisely, to the power relationships which make things possible or impossible.

We deal with the first question by studying the way common knowledge is built in a collaborative encyclopedia, namely Wikipedia, which greatly leverages on the properties of hyper-connectivity of the network. Note that, with modern computers and telecommunication networks, the role and the status of experiments are changing, which contributes to an epistemological breakthrough (Ganascia 2008) and therefore on the construction of knowledge. However, what we are interested in here is not the way new knowledge is built by scientists, but the way common knowledge is disseminated to the whole society when traditional authorities are no longer valid.

The second question is illustrated by a very particular example, which is the surprising evolution of patients' associations with improvements in communication technologies. It clearly illustrates the new forms of solidarity that emerge in a networked society. Lastly, we deal with social recognition, which is the ultimate hope of humans, in a society where the abundance of information blurs the contributions and merits of all kinds.

\section{G-rid Democracy}

\subsection{Evolution of the Social Fabric}

With the development of communication technologies, the interlacing of inter-individual relationships has become progressively intricate and difficult to comprehend. During thousands of years relationships have been mainly hierarchically structured by families or tribes, and more or less anchored on territory. 
The invention of scripture, horse transportation, printing techniques, the compass, the triangular sail, steam machines, the telegraph, the radio, the telephone and now the web have each contributed to the extension of human interactions into wider spaces (Poe 2011). Authority relations have expanded in scope from family, group, tribe and city to kingdom, nation, empire, continents, etc. And communication tools played a central role in these political transformations. In parallel with the extension of the scope of social interactions, societies have often admitted simultaneously different powers, e.g. temporal versus spiritual, local versus global, corporate versus central, etc., concomitance of which has been facilitated by the development of communication technologies. For instance, printing techniques played an important role in the dissemination of ideas, which contributed to the rise of Protestantism. In the same vein, the decreasing cost of paper and the industrialization of print processes in the nineteenth century allowed the emergence of a broad audience popular press.

Here, we attempt to draw a parallel between the social fabric, which results from the interlacing of individual relationships, and distributed computing. More precisely, to record the structure of modern societies, we refer to the topology of computer networks and the architecture of parallel machines. We hope that this will help us see the "OnLife" human condition from a new and fruitful angle and that this could also help to clarify the notion of hyper-connectivity, referred to above.

\subsection{Diffusion Modes}

It appears obvious that the connections between humans depend on their ability to exchange information and the way they communicate, both greatly affected by the development of ICTs. Classically, telecommunication engineers distinguish different modes of diffusion: unicast, where the exchange of information comes from one point - the sender - to one another - the receiver-, broadcast, where one point - the sender-sends simultaneously to all other points, and the multicast, where the information is distributed from one point to a selected set of receivers. Those modes can easily be reused to qualify human communications, which can be assimilated either to inter-individual, i.e. to unicast, or to collective exchanges, i.e. multicast. However, natural communications do not allow exchange from one person to all, that is to say, in technical terms, to broadcast information. It is only with mass media, at the end of the nineteenth century, i.e. with the development of newspaper, and, the twentieth, with radio and with television, that broadcasting took off.

Note that, in addition to these different modes of diffusion, which define different logics of communication, spatial proximity plays an important role, or more precisely, played a crucial role during thousands of years while, today, with electronic communications, it plays no role at all. More precisely, technological enhancements considerably increase the scope and the speed of information exchanges, ultimately making all the communications quasi-instantaneous on the surface of the earth. 
Lastly, there are multiple communication networks that may coexist simultaneously, which does not mean that everybody has access to all of these networks. Indeed, for different reason related for instance to physical proximity, the language used, the necessary equipment, etc. between networks are barriers that are difficult to cross. However, with the Internet this multiplicity of co-existing networks tends to be reduced. To illustrate this, let us remind ourselves that the word Internet is an abbreviation of the inter-network locution, which means that this network originally constituted an attempt to connect all previous existing networks.

\subsection{Network Topology}

The network topology corresponds to the arrangement of nodes through connections, i.e. to the structure of the network. It may be highly or weakly connected and more or less centralized, which corresponds to different shapes. Among the most current forms, we can include rings, stars, buses, hierarchies, trees, mesh networks, partially or totally connected graphs, etc. In addition to the shape, cardinality, i.e. the size, and the degree of nodes, characterize the network. The shape depends heavily on the mode of diffusion. For instance, unicast gives birth to topologies like rings, while broadcast facilitates the emergence of stars and multicast generates hierarchies. It also appears clear that the two last network characteristics, i.e. cardinality and the degree of the nodes, are strongly influenced by the development of technologies, which considerably increase the number of people to whom each one can be connected.

The topology certainly impacts power relations, which, in turn, influence political forms in a way that is not yet fully understood. For instance, writing was invented in Mesopotamia for the sake of the Royal administration, which hoped to centralize information. By the turn of the eighteenth century, the development of printing techniques and public postal services based on modern transportation (mail coach and railways) contributed to the creation of hierarchically organized networks that have enforced the power of administrations. The development of broadcasted mass media in the twentieth century with radio, movies and television, helped totalitarian regimes to prevail using propaganda. However, writing was not only used by the central power in Mesopotamia and poets very soon took advantage of writing to play with words and signs (Glassner 2000). Moreover, in the twentieth century, the sole purpose of broadcast was not to enable totalitarian regimes to enforce their power over individuals.

Today, the web constitutes a fully connected network that covers the entire planet. Its topology is studied by a new network science that tries to understand the properties of big graphs. Besides the size of this network and its "Deterritorialization" (i.e. the fact that connections are independent of land), the mode of diffusion of the Internet, that is mainly unicast and multicast - in contrast with mass media, essentially broadcast - greatly transforms the shape of the network, breaking classical well-ordered topologies like stars, rings or hierarchies, to become a huge meshed network. 
The web will certainly affect political forms; some people claim that it will give birth to a new participative democracy, under which the influence of the nation is diminished or where sovereignty no longer stands. Nevertheless, the recent emergence of populism in Europe shows the weakness of these assumptions. It goes the same, with the reinforcement of traditional Islamic parties after the Arab Spring, in Middle East and in many Arab countries (e.g. in Egypt, Libya, etc.) where authoritarian regimes have been overthrown. To conclude, we cannot extrapolate the exact nature of transformation from an analysis of the topology of the network, neither can we use it to further characterize the state of society as, in itself, the topology is static and consequently does not reflect social processes and the part they play in evolution of society.

\subsection{Institutions as Processors}

To approach the social dynamic, I propose to refer to institutions viewed as relatively stable formal social structures that are intended to play a role in society. This definition of institutions is sufficiently vague to be discussed, but the purpose here is not to give a precise account of this concept. We just want to examine the social structures in charge of coordinating human activities such as family, school, university, police, justice, etc. Each of those institutions has a function, for instance, the family is concerned with reproduction, the school with education, the police with repression, justice with the punishment of law infringement, etc. To achieve these functions, institutions can be viewed as processors that have tasks at their disposal. For instance, schools provide teaching, justice considers breaches to the law and puts people in jail or makes them pay fines, the police arrest criminals, etc.

In ancient times, when people were grouped in tribes, cities or small kingdoms, decisions were centralized in a unique place, the agora, the senate or the monarch's palace. Using a computer metaphor, we can then assimilate institutions to single processors, eventually to multi-task processors, when the same institution, for instance the agora, has different functions.

However, with the geographical extension of political entities, the increasing number of people and the multiplication of tasks, institutions cannot work undivided in one place. They need to split and work in parallel. Therefore, it is possible to analyze institutions as parallel processors.

\subsection{Parallel Computing}

Before going into the detail of the analysis of institutions as parallel processors, let us remind ourselves that people classically distinguish data flow and instruction flow, both of which can be single or multiple. This gives birth to four possibilities that are, SISD (single instruction, single data), SIMD (single instruction, multiple data), MISD (multiple instructions, single data) and MIMD (multiple instructions, multiple data). Further, along with grid computation, has recently appeared the possibility to distribute computation on myriads of distant processors that are available through the Internet. 
As previously said, classical institutions can be assimilated to SISD, since they work as a central processor, but, as soon as the task becomes complex, assemblies tend to divide in specialized commissions and working groups. In the latter case, the institution can be viewed as MISD, because different algorithms, based on different background knowledge, work in parallel on the same set of data.

It may happen that some institutions have to apply the same procedures on different data, which corresponds to the SIMD architecture. This is obviously the case with schools having to teach the same things to different pupils organized into different classes. It's also the case with justice, which has to judge all violations of law with the same rules.

Lastly, some modern institutions can accept simultaneously multiple instructions and multiple data (MIMD). However, whatever processor architecture corresponds to institutions, it is usually well ordered in a way that prevents conflicts.

\subsection{Grid Computation and Modern Democracy}

As previously said, due to the many computers connected on Internet, it is now possible to distribute computations to all distant processors available through the web. This corresponds to the grid computation, mentioned above, which allows freely sharing of heterogeneous and delocalized resources.

With the Internet, traditional institutions, and especially democratic institutions that contribute to government, for instance assemblies, voting, etc. tend to be highly transformed. The notion of political representation, which has been rendered necessary because of the difficulties to communicate, tends, more and more often, to be substituted by stakeholders, which can be non-governmental organizations, private societies, associations, etc. As a consequence, the general architecture that corresponds to the new social landscape is no longer hierarchical, neither circular nor "starred", but meshed, because connections are more or less randomly created between institutions, as required, no longer with geographical, moral or legal constraints.

Besides this meshed topology, institutions perform tasks on demand, according to their own agenda and to their availability. This results in a totally distributed and delocalized scenery, corresponding to the grid computation model. Put otherwise, the general model on which democracy is based is no longer a centralized democracy as in Ancient Greece, with institutions like the agora. Neither is it a representative democracy based on the legal institutions of the Modern Age with assemblies, voting, constitutions etc. It corresponds to a new form of democracy that we shall call "Grid Democracy," because its structure reflects grid computation architecture, i.e. a meshed topology and a distributed and delocalized decision processes.

\subsection{G-rid Democracy}

To conclude, let us recall that computer scientists know that changing machine architecture requires changing the algorithms. The introduction of parallel computation 
forces us to rethink the processes that solve tasks, according to the type of parallelism used (SISD, MISD, ...). Sometimes, this may lead to very efficient solutions, but not always; in any case, whatever happens, we need to totally rewrite the programs according to the type of parallelism that is implemented.

It seems to be the same with "grid democracy": the procedures that democratic institutions implement, like voting, decisions, public consultation, etc. need to be re-thought and rewritten. In a way, this appears to be very positive, because the old hierarchies and traditional authoritarian relations seem to disappear, which means that with "grid democracy" the democracy gets rid of ancient and cumbersome constraints. But, in this way, democracy also gets rid of many traditional democratic institutions and the fear is that this might leads to democracy itself being got rid of.

\section{Wikipedia, a Realized Utopia}

\subsection{Evolution of the Editorial Governance}

With the development of ICTs, the physical constraints related to the production and reading of books were significantly reduced. Very soon, many rejoiced in the new possibilities that seemed to be opening. They saw a great flexibility in the development and updating of encyclopedias and their consultation. They also saw the possibility to greatly reduce manufacturing and distribution costs, since it was no longer necessary to resort to printing on paper. Very early, some hoped to exploit these techniques to transform the validation procedures and to have the reader play a more important role in the creation of encyclopedias. Some even imagined that everybody would be able to freely contribute to the content of encyclopedias.

More precisely, the structure of the Internet allows readers to participate in the writing process by giving their opinion and by initiating or modifying articles. Readers become writers and may decide for themselves the items they want. The role of publishers is then transformed: they don't create order any more. They arbitrate conflicts between authors/writers and ensure that the basic rules of ethics, for instance the rule of neutrality, are respected.

This has resulted in new forms of editorial governance for encyclopedic corpuses characterized by a reversal, more or less extensive, of the social hierarchy for the administration of these projects. This text gives an account of the governance of some of encyclopedic editorial projects, notably that of Wikipedia.

Note that in the beginning, many of the well-informed specialists thought that it was impossible to make the reader a writer. For instance, I organized a working group in 1995 on the evolution of books (Ganascia 1995). While some had suggested the possibility, with the web, of building an open encyclopedia, the most eminent specialist in this group, Sylvain Auroux, a famous linguist and editor of many collective books and encyclopedias, affirmed that an encyclopedia needs a closure. What is interesting with the Wikipedia project is that it has denied such 
authoritarian claims. However, as we shall see, it substitutes a new social organization for the old one, which is interesting to analyze.

\subsection{Traditional Governance of Editorial Projects}

To understand what has happened, let us first recall that the word "encyclopedia" comes etymologically from "cycle": an encyclopedia aims to surround and to enclose all the human knowledge at a given time. To this end, use is made of the best specialists in all the fields of knowledge. The Encyclopedia of Diderot and d'Alembert, in the eighteenth century, is quite illustrative of this idea: it has resorted to 160 contributors, with various training and jobs. Together they wrote 72,000 articles.

To implement such a project, a rigorous organization had been erected. The Encyclopedists have distinguished three functions between which they established a strict hierarchy:

- Publisher: responsible for recruiting authors, ordering and monitoring their work,

- Authors, appointed and controlled by the publishers and

- Readers, who were neither supposed to contribute, nor participate in any way to the making of the encyclopedia.

The publishers ordered the authors to write articles on pre-specified topics. The authors made their copy under the authority of publishers and had to revise their contribution according to the publishers' comments. Finally, the readers were happy to get the finished product, without intervening at any time in its realization.

\subsection{Facilities Induced by ICTs}

With the introduction of ICTs, many technical constraints that had influenced the realization of traditional encyclopedias were lifted. Briefly speaking, below are some of these disappearing constraints.

1. It is no longer necessary to print an encyclopedia for broadcast.

2. Since there is no mass printing, the cost of distributing the encyclopedia is extremely small, ultimately becoming quasi-negligible.

3. The encyclopedia is accessible anytime, anywhere, without any routing problem. As a result, the potential audience is vast, since all humans who read the language in which the encyclopedia is written are likely to use it.

4. With the point-to-point communication, readers can easily send comments and exchange on the articles they read. They can also rewrite them. 
These four points have two major consequences:

1. Since the cost of production and distribution are virtually nil we can easily multiply versions, to the point of making local changes whenever it seems appropriate, without waiting for a global revision. Nothing prohibits a permanent rewriting or even a continuous writing of the encyclopedia.

2. Since readers can send their comments, nothing prevents us to take advantage of their contributions and-why not?- to offer them the opportunity to write articles and become authors.

All of this leads to evolve the classical triad "author-publisher-reader" (Ganascia and Lebrave 2002). The results of these changes have brought about new modes of governance for the editorial process. However, technology is not deterministic: it does not induce a single mode of governance; several online encyclopedic editorial organizations coexist today. Not to extend the text of this contribution too far, we restrict ourselves here to the depiction of the governance model for Wikipedia, but there are many others (de Laat 2011).

\subsection{Wikipedia Editorial Governance}

The Wikipedia model was developed from 2001. It has totally changed the game by claiming to refuse any social hierarchy and any form of stratification.

To assess the impact of this model, it is difficult to speak of success or achievement, because it is a massive social phenomenon.

The numbers speak for themselves: more than 4 million articles in English (September 2012), over 22 million articles in 285 languages, 77,000 active contributors and some 470 million visitors per month (February 2012).

Behind this surprising success, there is a social project. The designers of this encyclopedia purport to create a new form of democracy based on a model of selforganization completed by a few basic ethical principles, for example, the requirement of neutrality and the prohibition on intervention in an article on an issue that concerns us directly.

More precisely, the encyclopedia Wikipedia involves different categories of actors that perform different function, but between which it claims not to establish any hierarchy, rather just regulations or rules:

- Jimmy Wales, nominally in a position of ultimate authority,

- The arbitration committee (15-18 members)

- The "Bureaucrats" (34)

- The Administrators (700 vicinity),

Note that administrators, "bureaucrats", and Arbitration Committee shall ensure that the principles of the encyclopedia are respected. They do not intervene in the article contents. 
- Thematic editors (elected-70-80\% acceptance rate), these support items they monitor developments

- Contributors (77,000 registered)

- Registered readers who vote,

- Visitors (15 million visits per day in February 2012), finally,

- Bots (i.e. intelligent artificial agents) that automatically correct spelling errors, syntax or presentation items.

This organizational structure is completed by oversight mechanisms. Through them, specialized editors examine the corrections of the items they support so as to locate abnormal activities, which are mainly recurring corrections on the same items. This helps to fight against what the developers of this encyclopedia use to call "vandalism" and which consists, for the most part, in large corporations or associations altering articles that concern them in order to improve their image.

So regularly there are representatives of institutions, corporations, political parties or philosophical positions (e.g. creationists), who attempt to correct articles on themselves more or less directly, which goes against the principle of neutrality on which Wikipedia relies. Considered inconsistent with the basic ethical rules, such behaviors are strictly condemned. Users considered as guilty are no longer allowed access to the encyclopedia. More precisely, they can continue to consult the encyclopedia, but are not able to edit and to modify articles related to their business.

\subsection{An Unexpected Success}

In conclusion, let us first recall that the success of Wikipedia was very unexpected. Before Wikipedia, the models of collaborative encyclopedias, which were based on free and spontaneous public contributions, surprised most of the experts in encyclopedia publishing. For them, it was more of a naive utopian view than a possible reality.

As a consequence of the success of the new models, it seems that old models, based on respect for skills and knowledge, are at risk of disappearing. Moreover, the new models, especially the one that Wikipedia represents, raise many questions about the status of knowledge in society, its financing and control, and on those who can and must exercise control. In this regard, there is concern that low-skilled groups, groups funded by governments or private pressure groups outweigh experts. Or, conversely, that the rules too strictly applied restrict the freedom of authors.

Regardless of these issues on the new status of knowledge in society, we have here a concrete example of a modern model of governance brought about by the development of ICTs. This model of governance is interesting by itself. But it could also be generalized to other online institutions. 


\section{Fortunes and Misfortunes of Patients' Associations}

\subsection{Preliminary}

The previous section consisted of a description of the Wikipedia encyclopedia, a concrete illustration of a new type of utopia realized thanks to the use of information technology. This new section confronts ideas from May 1968, a period propitious to generous social utopias, to the current evolution of the society. We consider here another concrete illustration that is focused not on the editorial process, as in the case of Wikipedia, but on the evolution of the health system and its organization, in particular on the evolution of patients' associations. It illustrates how solidarity relationships can subsist on the networked society and how some people promote new principles of ethics.

\subsection{Brief Historical Recall}

Less than half a century ago, in almost all western countries as in the socialist world and the developing nations, social roles were well-defined: the teachers were there to teach, the physician to cure, the police to ensure public order, the politicians to govern, etc. During May 1968 in many developed states of Europe and in the United States of America, the young generation contested the legitimacy of the traditional social roles and the genuineness of all kinds of authority. The power of the police, the judges, the doctors, the professors etc. was questioned and debated. In the years that followed, society was traversed by attempts to change the social fabric, in a way that has led to a decrease in the power of traditional authorities.

The development of computer networks originated at the same time, in the late sixties, with ARPANET, which was supported by the DARPA (Defense Advanced Research Projects Agency). There was no direct connection between the militaries who had funded ARPANET and the political activists at the origin of the events of 1968. Nevertheless, a few years later, in the seventies and in the eighties, people, who had been strongly influenced by the ideas of May 1968 in their young age, greatly contributed to the development of computer and network technologies (Lyotard 1984). In particular, some of them initiated the free software movement, the purpose of which was to institute a new economical order based on a social utopia that was characteristic of that period (Turner 2006).

There naturally follows from these considerations a question about the very nature and the origin of the OnLife society, i.e. about of the society that is shaped by the information and communication technologies and, more specifically, by the web: Does the structure of this society correspond to the spirit of free movements of May 1968? Or is it fundamentally different, and why? In favor of the influence of May 1968, one can note that many traditional and well-established institutions seem to lose their credit. The web facilitates retroactions and interactive relations 
between actors, which prohibits unidirectional influences. For instance, some applications like "rate my professor"1, "review your lawyer", "rateMDs" (rate Medical Doctors $)^{3}$ etc. allow any student, any consumer, any patient etc. to give publicly their own evaluations of authorities. In addition, the development of cheap and light cameras $^{4}$ and their coupling to the web enable anyone to capture and to broadcast sensitive information about authorities, for instance about a policeman who beats people on a metro platform, without the mediation of intermediaries, like journalists. As a consequence, state institutions, newspapers, media and authorities tend to loose their exclusive privileges. More generally, the dominant status of the officially stated knowledge may be publicly discredited on networks. All of this might incline us to conclude that the networked society realizes the spirit of May 1968. However, against this thesis, we note that the unbalanced power of the market has never been so important and that social solidarity and public generosity seem to decline.

To try to answer the question relevantly, we explore here the specific question of health maintenance and its recent developments. In particular, we are interested in the social organization of health systems, in the evolutions of the authority of physicians and health industries, and their influences on medical cares.

\subsection{Medical Nemesis}

As an introduction to this question, let us consider the work a famous essayist of the seventies, Ivan Illich, who was representative of the state of the opinion during this period. He wrote many controversial books on very different topics; for instance, he brought into question the role of public education and the school (Illich 1971), the benefits of technology (Illich 1974a, 1978a, 1995), the necessity to work in (Illich 1978a, 1978b), etc. He has also denigrated the medical institution in a famous book entitled "Medical Nemesis" (Illich 1974b) where he denounced the omnipotence of medical knowledge, which was quite unusual at this time. More precisely, he said that most of the successes of which the physicians prevailed in the second half of the nineteenth and in the twentieth century were illusory, because they were not really due to modern medicine, but to social progresses, to hygiene and to the evolution of the standard of life. In contrast, he blamed the medical authorities who, according to him, were not only responsible for the induction of iatrogenic diseases, i.e. of diseases that result from treatments or therapies, but also of human engineering, which has led to what he called a social "iatrogenesis", i.e. to the development of a social life and of an economy under medical control and under the domination of

\footnotetext{
${ }^{1}$ http://blog.ratemyprofessors.com/.

2 http://www.avvo.com/review-your-lawyer or.

3 http://www.ratemds.com/.

${ }^{4}$ As an illustration, one may mention a wearable camera named nemoto ${ }^{\mathrm{TM}}$ (http://memoto.com/), or another name autographer ${ }^{\mathrm{TM}}$ (http://www.autographer.com/) but there are many others.
} 
the health industry. In other words, he accused the medical body of not taking into account the real needs of patients, but only their own interests.

Ivan Illich proposed a few solutions to make the social organization of health more health-serving than industry-serving. Among them, he supported the recognition of many health professions, like herbalists, masseurs or yoga instructors, against whom he called the "Professional Mafia" of physicians. He also recommended the promotion of health maintenance rather than sick-care and payment with a fixed amount per capita rather than a fee-for-service. But, the most interesting suggestion for us here was to stimulate a patient-oriented medicine, rather than a milieu-centered medicine. He then encouraged patients to organize groups for exchanging information about their diseases and how to live with the disease, and also for pressing governments to give public funds for research or industries to design new therapies, more adapted to their cases.

Then, in the seventies and the eighties, associations of patients for specific diseases, especially chronic diseases, were formed to help ill people face the consequences of their pathology by exchanging information about treatments and practical aspects of social life and sustenance. At this time, there was no web, but the patient associations took advantage of the progress of information and communication technology, especially the telephone, to help exchanges, and the radio to advertise the associations.

\subsection{Forty Years Later}

Forty years later, there are tens of thousands of patient associations ${ }^{5}$, which all use information and communication technologies to ensure their promotion, to exchange knowledge and to educate people. These associations not only help patients to get practical information about their disease and the most appropriate treatments, but they act as lobbies and stakeholders in the health domain. For instance, they press public authorities to fund specific treatments and research; they urge pharmaceutical industries to develop new drugs; they force regulators to speed up evaluation procedures to facilitate the adoption of new medications; they analyze research protocols; they expose side effects of treatments etc. The case of AIDS was particularly illustrative: very strong associations of patients forced medical, industrial and public authorities to boost research and to accelerate administrative procedures, to provide new treatments that have totally changed the outcome of the disease.

More generally, patients' organizations take part in the negotiations between state authorities, research organizations and pharmaceutical industries. They are considered as official actors, which gives them power and recognition. In this regard, the proposition of Ivan Illich, which was to promote groups of patient to impose public control over the organization of medicine, has been granted. We could conclude

\footnotetext{
${ }^{5}$ For instance, the French HAS ("Haute Autorité de la Santél") has counted more than 14,000 associations of patients for the only France.
} 
from this that the spirit of May 1968 won. And, undoubtedly, things have considerably changed due, in part, to the use of modern information and communication technologies, which greatly facilitates the retroaction of patient's associations in public debates and the mobilization through the network of disseminated patients, who can now exert a strong pressure in case of need.

However, recently, many people (Colombo et al. 2012; Mosconi and Colombo 2010; Rothman et al. 2011), have denounced the opacity of patient association funding, which comes partly from industries. To clarify this point, let us recall that, when a patients' organization grows up and augments its influence, it needs to employ full time administrators, who quickly establish a kind of bureaucracy, whose aims are a long way away from patients' interests: quite naturally, these administrators become mainly occupied with the influence of their organization, which justifies their employment and satisfies their personal ambitions. As a consequence, their prior concern is that their organization be considered as an essential stakeholder, and then that it be involved in the main decisions, even if this activity has no direct relationship with patients' interests and care. For instance, they want to be involved in new clinical trials and in the discussion with health care organizations about reimbursement of treatments. It may then happen that industries would secretly negotiate with patient's organizations to constitute coalitions of interests against state organizations or against physician organizations. In such cases, the patients' organizations no longer represent the interests of patients, but their own interests, which may coincide to the interests of pharmaceutical industries, because they give them funds. It follows that the current situation looks to be far away from the spirit of May 1968, even if the patients' associations oppose to the body of physicians and its domination.

\subsection{The Shattering of Institutions}

As already mentioned, the patient's associations take advantage of the web to increase their influence and to disseminate information to their participants. Since the web allows the direct mobilization of the people, it certainly leads patient's association to increase their influence. This is consistent with the idea that traditional institutions, like medical authorities, now need to share their influence with new actors. In the case of patients' organizations, it means that people, affected by the same disease, can now be connected throughout the web and exert a strong influence, while in the past, they would have remained isolated.

Nevertheless, with the development of the web and, in particular, with the participative web, new phenomena happen that make the official status of both patients' and physicians' organizations more difficult.

To understand the current situation, let us recall that, as previously said, as they grow up, the patients' organizations are moving away from patients' interests, towards their own interest, that is to increase their influence. Therefore, individual patients are less and less motivated by these organizations. In addition, they now become able to get information by themselves, throughout the web, and to get in 
touch directly, through social networks, with other people that are affected by the same disease, with whom they can easily share their experiences. As a consequence, we observe that many patients leave patients' organizations. Paradoxically, these last are always official representatives of patients in public negotiations, although many patients are not affiliated. In other words, the patients' organizations that have become progressively recognized as official institutions shatter under the effect of the Internet that allows patients to connect and interact each other, without their mediation.

In parallel, some physicians, who are not well recognized by the official bodies of their profession, have taken advantage of the web to constitute themselves as advice givers. They promote, via medicine $2.0^{6}$, new approaches of medicine that allow patients themselves to take charge, by being informed about their disease and possible therapies, and by adapting their treatment to their needs, according to their own knowledge and personal choices. Without going into the details of this new medical practice, which include self-medication, i.e. the process of prescribing treatment oneself, note that it is very often opposed to institutional medicine, while meeting the needs of patients who are seeking for information on the web. Besides, it is noteworthy that today, because of access to scientific knowledge through the Internet, many patients affected by chronic diseases have a better knowledge of their pathology and of the state of the art in the care of their condition than their own medical practitioner.

It follows from this that the body of physicians, which had been forced to negotiate with different actors, after having dominated alone the whole health system for a long time, is now burst in the same way as patients' organizations. These phenomena correspond to recent, unexpected and unpredictable social change. This unpredictability renders it difficult to answer our initial question, which concerned the parallel between the recent evolution of the OnLife society and the utopia of May 1968. On the one hand, it is certain that information technologies have deeply changed society and have contributed to destroy the privileges of the old institutions like those of medical academies; on the other hand, it's not obvious that the current evolution truly corresponds the ideals of May 1968.

In conclusion, let us consider the current configuration where isolated patients are seeking information about their disease on the web, while some physicians disseminate information by themselves, without referring to the knowledge of best specialists of their domain. The two parts are obviously complementary. However, it may then happen that erroneous knowledge circulates, while authorities, even when they give correct knowledge, are discredited. That's what happened 2 years ago, when many general practitioners were opposed to the public vaccination proposed by the French government, because they where not involved in this plan. They then disseminated misleading knowledge about the danger of the vaccination through the web (Dupagne 2010), with the aim to provoke the failure of the government plan. It fast became very popular; for instance, one of these papers has been

\footnotetext{
${ }^{6}$ The http://www.doctissimo.fr/ and http://www.atoute.org/ web sites are excellent examples of such approach of medicine. Note that Atoute.org explicitly mentions the Medicine 2.0.
} 
downloaded more than 1.5 million times. Following this, the public vaccination plan proposed by the government completely failed because the population did not accepted it. It is certain that these general practitioners played a role in this failure.

This illustrates the power of the Internet and the way it changes state policy, that is, in our case, health policy. This also shows how the Internet affects the role of authorities, in particular scientific authorities. Lastly, this provides evidence of the crucial need for networked society, where institutions and organizations tend to collapse, of an epistemic responsibility like the one that is developed by Judith Simon, to ethically condemn the dissemination of wrong knowledge, as it was the case in the case above.

\section{The Digital "Aura" in a World of Abundance}

\subsection{From Scarcity to Abundance}

Twenty years ago, I had a dream that was to live day and night, especially the night, in a library. Today, this dream has become a reality: we all live in a huge library, where almost all the written books of the classical literature are instantaneously accessible, by day as by night. By the way, the world of knowledge is dramatically changing. It's becoming a world of abundance where all pieces of information are permanently at the disposal of everybody. To appreciate the amplitude of the evolution, let us have a glance into the past. Up to the end of the Middle Age, books were so expensive and so difficult to manipulate that only the happy few had access to them. In addition, this access was not permanent: it was required to be through a library or a monastery, which precluded access during travels, even for the richest. In the modern age, printing techniques allowed the reduction of cost and size of books and consequently their dissemination. However, despite these improvements in manufacturing, books were always expensive and inconvenient, which restricted their access to a small part of the population. It was only with the industrialization of the printing techniques, at the end of the nineteenth century, that the literature, the newspapers, the philosophical and scientific essays and more generally all kinds of writings have begun to broadly disseminate across all society. In parallel, the techniques of lithography, invented at the end of the eighteenth century but which have received a considerable development during the nineteenth century, considerably facilitated the reproduction of pictures, which was largely used to enrich books, newspapers and posters. Lastly, photography, invented in the second quarter of the nineteenth century, and then the phonograph and cinematography, both invented by the end of the nineteenth century, allowed progressively the automatic reproduction of pictures, sounds and movement.

Nowadays, with the development of information technologies, the movement of mechanical reproduction seems to have been considerably amplified. It is neither surprising, nor new: this had already been anticipated in the twentieth century by 
thinkers like Paul Valery in 1931 in a small text entitled "La conquête de l'ubiquité" (Valéry 1928). However, today, the quantity of available contents exceeds, far more than ever, our cognitive abilities. It results in modifications in our perception of works of the mind in general and of works of art in particular. Do these transformations simply prolong and extend the movement initiated in the nineteenth century with the mechanical reproduction or do they constitute a new qualitative step that characterizes entering into a world of abundance? That is the question we would like to discuss here.

\subsection{The Loss of the Aura}

Economical, political and aesthetic consequences of the mechanical reproduction of writing and images have had considerable effects on modern societies during the twentieth century. It is not only access to works of the mind and, in particular, to works of art that has been facilitated, but the nature of their intellectual content and the way in which they influence humans that has been transformed (Benjamin 2006). On the one hand, physical objects of art, e.g. the physical support of pictures, were becoming far less valuable because of their easy reproducibility. Therefore, what had been previously attached to unique and singular items, which because of their irreplaceability conferred on them, some magic properties, was disappearing, which made the nature of art evolve. A famous essay written by Walter Benjamin in the second quarter of the twentieth century and entitled "The Work of Art in the Age of its Technological Reproducibility" (Benjamin 2008) constituted an attempt to approach the nature of these changes. It has been very influential during the last 60 years especially, but not only, in aesthetics. According to Walter Benjamin, with the mechanical reproduction of works of arts, in particular with photography, the part of the human in the making of art was greatly reduced, because the capture no longer required the intervention of human hand, since the machine was automatically recording the light. As a consequence, works of art, which had testified to an inheritance and a tradition since the origin of mankind, both by the art techniques utilized, which required to learn gestures, and by the symbolic references attached to the contents that were almost always conventional or allegoric, have became, with these new inventions, closer to scientific investigations than to the sacred and supernatural. It follows that prosaic objects of everyday life turned more and more often to be referents of works of art. Baudelaire, who described the Paris streets, and Stéphane Mallarmé have attested this evolution in poetry (Benjamin 2006). But, it could have been possible to see many other manifestations in different arts. In addition, the reception of works of art was evolving with their massive reproducibility: it became collective and simultaneous, with photos or movies, while previously it had essentially been individual and contemplative.

A key concept proposed by Walter Benjamin to approach these transformations was the notion of aura, which he defined as "the unique phenomenon of a distance, however close it may be." The notion of aura was also linked to the involuntary 
memory (Benjamin 2006), which had been introduced by Marcel Proust and Henri Bergson (Bergson 1926) to characterize a type of remembering that is both contemplative and unconscious, and that contrasts with an intellectual and active access that is implemented in the voluntary memory.

According to Benjamin, works of art are received and valued on different planes that stand between two polar opposites; on the one, the accent is mainly put on the cult value, that is associated with the contemplation, which requires concentration; on the second, the accent is put on the exhibition value of works of art that are designed to distract the mass of spectators and that no longer demand them to be absorbed. With mechanical reproduction, the cult value of works of art that requires concentration and efforts tend to decline while the exhibition value, which distracts the mass, becomes more and more prominent. As a consequence, the aura, which is attached to the cult value and to traditions, vanishes.

This loss of the aura is not only negative. It has aesthetic consequences. New forms of art that no longer refer to traditions and that eliminate cult value are emerging among which one can note Baudelaire's poetry, Cubism or Dadaism. But it has also less positive consequences that led political regimes - especially, the twentieth century totalitarian regimes - to use new media and works of art for their propaganda. Lastly, it has economical consequences that lead works of art to focus only on the exhibition value.

\subsection{The Digital “Aura”}

As we recall, Walter Benjamin announced the loss of the aura consecutive with the mechanical reproduction of works of art. The question, then, is this: Does the development of information technology leads to a definitive and total loss of the aura? In other words, are the information technologies only the pursuit of mechanical techniques? Are they simply amplifying their effects? Or, do they introduce a rupture? In the case of the aura, the question concerns its current status: has it definitively disappeared? Or, does some form of resurgence of the aura persist?

Undoubtedly, digital technologies perfect the reproduction processes of works of art. Thanks to these, reproduction is nearly free: nowadays, it costs neither a lot of money, nor large amounts of energy, to duplicate information. We could characterize this current ease to reproduce as being a state of hyper-reproducibility by analogy to the state of hyper-conductivity for the electrical conductivity.

Furthermore, diffusion is also practically free and accessible to everybody. Currently, it becomes possible for anyone to divulge in the entire world literature, pictures or sounds without having to ask for authorization and without owning any infrastructure, except a PC. As a consequence, today information is becoming eminently diffusible almost everywhere on the surface of the earth. For instance, in 2011, during Arab spring, young students sent, with no support, videos of the public events in Tunisia or Egypt, while 20 years before, in China, or in many other authoritarian countries, it had been impossible to send images of the dramatic event 
that were happening in the streets. Always by reference to the morphology of hyperconductivity, we shall characterize this state as a hyper-diffusibility.

Lastly, any pictures and sounds can be easily captured with very cheap equipment, like a mobile phone, and then memorized on small and inexpensive electronic storage devices. As a result, and by the same way of previously, we can say that we enter in a world of hyper-memorisability.

All the techniques of reproduction, diffusion and memorization that had so greatly contributed to the disappearance of the aura have been so considerably improved that the result exceeds our cognitive abilities. As a consequence, our faculties of discernment are insufficient. The total available content cannot be consumed by the human mind, even helped by powerful machines. In other words, it is becoming more and more difficult to filter the flow of data that assails every one of us, each day, and to focus on the relevant information. Therefore, we have to make choices, to decide on which object we will focus our attention and then to select, among the many pieces of information that concern our object of interest, which ones we would prefer to explore. However, those different choices cannot be well informed, because they are anterior to our possession of knowledge. As a consequence, we choose according to some unconscious criteria that constitute a kind of halo - or a cloud - enveloping the objects and attracting our mind. Such criteria correspond to the above-mentioned involuntary memory; therefore, we call it the digital halo or the digital aura.

Note that, as we have previously shown in our work on sousveillance (Ganascia 2009 , 2010), this digital aura becomes increasingly important because, in our world of excessive abundance of information, the power is far more often given to those who are viewed than to those who watch.

Our hypothesis here is that we can draw some parallels between this digital halo and Benjamin's aura. Among them, note that while the aura requires concentration, it is same with the digital halo. Furthermore, as we previously said, while the aura was directly related to involuntary memory, it is also the case that the digital halo is largely unconscious.

However, as we previously mentioned, for Benjamin the notion of aura was directly related to the cult value, to an attachment to traditions and to a contemplative attitude. It might seem surprising and even strange to affirm that, with the digital technologies, we adopt a contemplative attitude oriented towards traditions. To be more precise, the first hypothesis, drawing a parallel between Benjamin's aura and the digital halo, needs to be complemented by a second hypothesis that states that, while Benjamin's aura was attached to a cult value, oriented towards traditions, the digital aura is attached to a specular value, which opens on new opportunities. In other words, while the cult value was oriented towards an immemorial past, the specular value is oriented towards an accessible and free future that is full of possibilities.

This notion of digital aura in relation to a specular value would be useful to interpret many of the contemporary movements in art, especially the generative art, which cannot be evaluated with respect to their exhibition value and no longer with respect to a cult value, but only with respect to the number of possibilities that a 
program can generate. It would be suitable to follow with some precise examples, which would justify the two preceding hypotheses, but this would be far in excess of this chapter.

Recall also that Benjamin's definition of the aura as "the unique phenomenon of a distance, however close it may be" could be directly applied to the digital aura. Nevertheless, while in the case of Benjamin's aura, close and concrete elements of works of art helped to give access, through contemplation, to a far past, anterior to what can be provided by any voluntary memory, with the digital aura, close and concrete information elements help to give access to a far future that opens on new perspectives, despite all perceived dangers and fears.

Open Access This chapter is distributed under the terms of the Creative Commons Attribution Noncommercial License, which permits any noncommercial use, distribution, and reproduction in any medium, provided the original author(s) and source are credited.

\section{References}

Benjamin, W. 2006. The writer of modern life: Essays on Charles Baudelaire. (M. W. Jennings, Éd.) Cambridge: Harvard University Press.

Benjamin, W. 2008. The work of age in the age of its technological reproducibility, and other writings on media. Cambridge: Harvard University Press.

Bergson, H. 1926. Matière et mémoire. Paris: Félix Alcan.

Colombo, C., P. Mosconi, W. Villani, and S. Garattini 2012. Patient organizations'funding from pharmaceutical companies: Is disclosure clear, complete and accessible to the public? An Italian survey. PLoS ONE 7 (5): e34974.

P. B. de Laat. 2011. Open source production of encyclopedias: Editorial policies at the intersection of organizational and epistemological trust. Social Epistemology 26:71-103.

Dupagne, D. 2010. Faut-il ou non se faire vacciner contre la grippe? Récupéré sur http://www. atoute.org: http://www.atoute.org/n/article134.html.

Ganascia, J.-G. 1995. Récupéré sur Rapport sur le livre électronique-report on EBook. http:// www-poleia.lip6.fr/GIS.COGNITION/livr.html.

Ganascia, J.-G. 2008. In silico' experiments: Towards a computerized epistemology. (P. Boltuc, Éd.). American Philosophical Association Newsletters. Newsletter on Philosophy and Computers 2:11-15.

Ganascia, J.-G. 2009. Voir et pouvoir: qui nous surveille? Paris: Editions du Pommier.

Ganascia, J.-G. 2010. The ethics of generalized sousveillance. ETHICOMP 2010. Tarragona: Universita Rovira i Virgili.

Ganascia, J.-G., and J.-L. Lebrave Éds. 2002. Back to the future knowledge management past and present. Diogenes, Vol. 49, No. 4. (1 April 2002), pp. 8-19. Blackwell publishing.

Glassner, J.-J. 2000. Ecrire à Summer. Paris: Editions du Seuil.

Illich, I. 1971. Deschooling society. New York: Harper \& Row.

Illich, I. 1974a. Energy and equity. New York: Harper \& Row.

Illich, I. 1974b. Medical nemesis. London: Calder \& Boyars.

Illich, I. 1978a. The right to useful unemployment. New York: Marion Boyars Publishers Ltd.

Illich, I. 1978b. Towards a history of needs. New York: Pantheon Books.

Illich, I. 1995. Blasphemy: A radical critique of our technological culture. Morristown: Aaron Press. 
Lyotard, J.-F. 1984. The postmodern condition: A report on knowledge. (G. B. Massumi, Trad.) Minneapolis: University of Minnesota Press.

Mosconi, P., and C. Colombo. 2010. Fostering a strategic alliance between patients' associations and health care professionals. (M. Norbert Goldfield, Éd.). Journal of Ambulatory Care Management 33 (3): 223-230.

Poe, M. 2011. A history of communications: Media and society from the evolutuion of speech to the internet. Cambridge: Cambridge University Press.

Rothman, S., V. Raveis, A. Friedman, and D. Rothman. 2011. Health advocacy organizations and the pharmaceutical industry: An analysis of disclosure practices. American Journal of Public Health 101 (4): 602-609.

Turner, F. 2006. From counterculture to cyberculture. Stewart Brand, the whole earth network, and the rise of digital utopianism. Chicago: University of Chicago Press.

Valéry, P. 1928. La conquête de l'ubiquité. CEuvres, tome II, Pièces sur l'art. Paris: NRF Gallimard, Bibiothèque de la Pléiade. 